\title{
Stories Have the Power to Save us: A Neurological Framework for the Imperative to Tell Stories
}

\author{
Bem Le Hunte $^{1^{\star}}$ and Jan A Golembiewski ${ }^{2}$ \\ ${ }^{1}$ University of Technology, Sydney, Australia \\ 2 Schizophrenia Research Institute, Australia
}

"Corresponding author: Bem Le Hunte, Associate Professor, Bachelors of Creative Intelligence and Innovation, University of Technology, Sydney, Australia, Tel: +61 (2) 9385 6355; E-mail: Bem.LeHunte@uts.edu.au

Received date: May 30, 2014, Accepted date: July 21, 2014, Published date: July 28, 2014

Copyright: (c) 2014 Hunte BL, et al. This is an open-access article distributed under the terms of the Creative Commons Attribution License, which permits unrestricted use, distribution, and reproduction in any medium, provided the original author and source are credited.

\begin{abstract}
The evolutionary advantage of humans is in our unique ability to process stories - we have highly evolved 'narrative organs.' Through storytelling, vicarious knowledge, even guarded knowledge, is used to help our species survive. We learn, regardless of whether the story being told is 'truth' or 'fiction.' Humans place themselves in stories, as both observer and participant, to create a 'neural balance' or sweet spot that allows them to be immersed in a story without being entirely threatened by it - and this involvement in story leads to the formation of empathy an empathy that is integral to forging a future humanity. It is through empathy, we argue, that stories have the power to save us.

The hippocampi process narrative details. Situated alongside are the amygdalae - organs that place the reader in the story. The temporal lobes store 'story nuggets.' Finally there's the frontal cortex to inhibit full participation in narrative, so that the story can be experienced vicariously.
\end{abstract}

Keywords: Storytelling; Empathy; Ipseity; Evolution; Narrative; Neuroscience

\section{Introduction}

When an invented character, fabricated by a writer of fiction, reveals a 'truth,' sometimes that truth can beg for greater scrutiny. The doctor who narrates the novel, There Where the Pepper Grows [1], Benjamin Rahabi, tells the story of his escape from Nazi occupied Poland to the welcoming embrace of Calcutta, on the premise that stories have the power to save us. He does so with the authority of a physician who has explored the dark edges of human storylines and the impact they have on the body. The claim that stories have the power to save us is audacious, yet it is one that can be validated by neuroscience. This article demonstrates that the brain is hard-wired to process stories in a most fundamental way, indicating the evolutionary priority that storytelling has had in human development, and the importance it has in forging a future humanity.

This article considers how human organs are devoted to narrative function. More specifically, it looks at the validity of fictional truth the way the human brain uses 'fictional worlds' to expand understanding about the 'real world' or phenomenal reality. It gives a neurological foundation to Kenneth Burke's notion that literature provides us with 'equipment for living.' That stories work as 'proverbs writ large' - helping us to understand the fundamentals of survival the workings of cooperation and conflict [2].

Supposing we were to treat the words of the above fictional character, Benjamin Rahabi, as a hypothesis. Is there any way to explore whether stories have the power to save us or not? Early thinkers like Charles Darwin and Herbert Spencer wrote that the lack of ability to adapt to events puts a species at an evolutionary disadvantage $[3,4]$. More recent research into the nature of the human brain pleads an evolutionary advantage to our capacity for narrative. Central to our evolution has been the development of 'narrative organs,' which we will discuss below.

The human brain, above all others, has the most developed ability to extrapolate meaning and implications from stories. Moreover, one of the great evolutionary advantages of being human is that we don't need to actually live through an event to gain the perspective of someone else's experience. We can identify a potentially disastrous or beneficial event because we can recognise these through story, mythology, recount and other narrative structures describing comparable situations. Moreover, dangers and opportunities don't have to be identical, as they would have to be for a dog or monkey (dogs salivate only to the sound of a bell - not the sound of a gong). Unlike animals, we can infer meaning from metaphors. We can translate scenarios into our own lives. We can imagine ourselves out of our familiar comfort zones into a situation where we are genuinely feeling threatened, even in a cozy bed with a novel in hand and a partner snoring nearby. These are the functions of a storytelling brain, which have developed over time, as an evolutionary imperative.

Not only does the human brain have this capacity, but it has some well-developed neurological mechanisms that have evolved to help us to store, recall and interpret situations and stories. These are located in two parallel sets of organs - the two hippocampi (on the left and right sides of the brain), which provide the capacity to store and recall episodic memory, better known to fiction writers as narrative. They do this by recording and recalling schemata or story nuggets, which are largely stored in the nearby temporal lobes [5].

Before we speculate on the narrative function of the left and right hippocampi, we should do so within the context of scholarship on the differences between the two. McGilchrist argues that the left side of the 
brain is used for processing focused intention [6]. He describes a bird using its left brain to look for seed [7]. The left hippocampus stores and recalls smaller, less abstract narrative nuggets. It's the narrative that's concerned with the functional and physical plane rather than the metaphysical plane. In other words, the left hippocampus is more tightly focused on what is going on right now - the so-called realities of a situation - the narrow context of the story. How is that bird going to get the seed? How is a character going to find her long lost brother who was given up years ago for adoption? Which physical location would characters go to if they were seeking spiritual enlightenment? [8].

In contrast, McGilchrist [7] asserts that the right side of the brain is used for processing global attention. The bird uses the right brain to look out for broader context and circumstances, such as danger. The right hippocampus stores and processes the meta-narrative in which every story has to take place. In other words, what this story means on a grander scale. The right hippocampus stores and recalls the notions of time, place and setting - the context of the story rather than narrative particulars - as well as the grand themes [9]. At the same time, it allows the reader to ponder over the bigger issues - the themes of the novel - and locate themselves in those themes. For example, if someone is reading Animal Farm [10], they will understand the analogy between the governance of the animal farm and the corruption of real life political elites. The ability to contextualise and step outside an immediate narrative, into an allegorical theme or metanarrative, gives the reader a sense of perspective - even distance on story.

In terms of narrative, one story is nested in another and both aspects of the brain contribute to a single picture. Similarly, in fiction, these two aspects of story are fully integrated in a seamless fashion within a single narrative structure. The reader absorbs a grand theme (right brain), whilst observing the purely functional movements of characters in a fictional setting (left brain).

Intersecting with the hippocampi are the amygdalae, a paired set of organs that sit directly against the hippocampi. These moderate the sense of ipseity - the location of the 'I' or 'me' in any particular story. The amygdalae are instrumental in creating a sense of whether or not we are involved in the story. As such, they are key processors of emotion [11].

Once again, the right and left amygdalae correspond with the global picture of the right brain and the specificity of the left brain. On a grand scale, and the grand scale is what is moderated by the right hemisphere, the right amygdala gives the reader contextual awareness - if they are reading a thriller, it allows them to think, "I am not at risk. I am reading a novel."

The left amygdala, simultaneously, tells us whether the story has any direct effect on us as individuals, right now - the prosaic reality. It's the organ that exerts the power of immediacy and imminence. The ipseity - or sense that this concerns 'me' (the vicarious experience) locates the audience in the anguish of the present circumstances (albeit via the experiences of the protagonist). In literary terms, it allows us to plant a personal perspective into the story as if it were our story. This type of ipseity allows us to watch the drama unfold while sitting on the shoulder of the protagonist. Directors like Spielberg actually film from the shoulder of the protagonist to get this sense of identification - the left amygdala telling the audience "this directly concerns me."

In a page-turner such as the Da Vinci Code [12], the reader is required to surrender the left amygdala to directly experience the trials of the protagonist, as if they were their own - as if they themselves were being chased around Paris by an albino Corpus Dei monk! All the time, the contextual ipseity that resides in the right amygdala would remind the reader that they are sitting in the comfort and security of their own home.

The contrast of what we would describe as dual ipseity (I'm in the action, yet observing it) has been recognised by many thinkers. Scholars as early as Aristotle, writing about catharsis, explained how tragedy served to purge the audience of similar emotions [13]. Kant observed how the overwhelming experience of awe is moderated by the knowledge that we are actually safe [14].

The ability to locate oneself in a narrative is an essential element of empathy. If one cannot feel the heartbeat of the protagonist as one's own, then either the author is implicated (for distancing the reader perhaps through experimental or meta-fictive devices, such as those used by Bertolt Brecht [15]) or the reader may be defined as someone who has lower capacity for empathy.

Neurological studies on empathy typically focus on the Theory of Mind (TOM), which outlines the capacity of one individual to comprehend and relate to another person's emotional state [11]. In the terms that we're discussing here, the Theory of Mind can only be constructed if there is sufficient dual ipseity to have a sense of ' $I$ ' (right brain) as well as a sense of ' $\mathrm{I}$ am transferred into the experience of another' (left brain). This ability to understand another person's 'Iness' is interesting. We can't say whether this comes from fiction or from socialisation, but either way it is this mechanism that allows us to empathise with each other, as well as with fictional protagonists. The very fact that Theory of Mind can be applied to real people as well as fictional people means that on a profound level, fiction provides an equally 'real' milieu for the human brain to develop emotionally and express its full humanity.

If the healthy mind organises narrative around a sense of 'I-ness' or ipseity, then a mind that doesn't is declaratively unhealthy. Neuroscientists Louis Sass and Josef Parnass propose that this loss of self is a neglected, but fundamental feature of schizophrenia [16]. Certainly, the loss of ipseity is characterised by the most extreme and troublesome cases of schizophrenia. The grueling first person account of schizophrenia by Clara Kean, recounts a time of complete loss of 'global' self. Even though the ipseity of mundane awareness remained, her sense of self was completely lost. "The real 'me' is not here any more. I am disconnected, disintegrated, diminished. Everything I experience is through a dense fog... It was not even my own distressI was totally separated from myself, not knowing what action I was taking" [17]. Schizophrenia appears to cause underactive amygdalae on both sides of the brain, but particularly on the right - perhaps explaining why those suffering are unable to locate themselves in their 'story' [18].

In contrast, in disorders that feature overactive amygdalae, such as in affective paranoia, patients find it hard to relate to others, primarily because they are manically fixated on their own personal 'story' and they transfer their 'character' into every conceivable scenario. Patients often find it very hard not to believe that every story concerns them, as a central protagonist. A classic example is the story of Chadwick, a schizoaffective patient who perceived radio and television commentators speaking to him personally, as if they were part of his internal narrative. "I listened to the radio 'for messages' a great deal in the summer of 1979" [19]. Balanced amygdalae are essential for understanding others, as demonstrated in many Theory of 
Mind studies. In this context, Chadwick says, "I had very little capacity to integrate thought and feeling," and that, "my gist and context processing were poor...I would often be accused of being tactless, cheeky, offbeat, saying inappropriate things [20]."

In cases of both affective and non-affective psychoses, there is ample evidence to suggest that the coupling of the amygdalae (the Iness), with the sense of story in the hippocampi, has gone askew. Too much or too little ipseity both seem to be problematic, as if there is some kind of sweet spot in between, where safety of observation can be combined with the terror of absorption - where there is enough ipseity to empathise, but not so much that personal concerns override those of the fictional protagonist.

A sensitive balance between observer and participant is required to promote engagement with story. Too much observer and there is no longer any 'fictional reality.' Too much participant and the story becomes scarily real - the vortex of story has swallowed the reader in the telling of the tale. The well-balanced work of fiction (not to mention, the well balanced life story) requires a type of neural balance that has not received much in the way of scholarly attention in healthy individuals.

In an evolutionary sense, this balance has been thousands of years in the making, which takes us back to our central premise that stories have the power to save us. Stories serve an important function in our lives, and stories are generated by our brains. Our brains turn the random nature of events and string these into meaningful narrative. Stories are all about what directly impinges on our humanity. We see the world in terms of story, and this creates the world we see. In other words, the world becomes full of stories - sometimes they are our own and sometimes they belong to others, but we recognise these stories and follow them with deep fascination, which must have been the evolutionary foundation of empathy. As Aristotle points out, in a great tragedy like Oedipus Rex, the audience can identify that there is a disaster looming, and regardless is hooked on seeing it unfold. Yet if this tragedy were to happen in real life, probably few would want to watch it.

Throughout evolution, stories have had the power to save us, because instinct is tied to narrative. If evolution is all about the survival of the fittest, then we have to be fit enough to tell stories. Thanks to storytelling, evolution can take place in a single lifetime. You don't need to die of thirst to realise that going into the desert without water is a bad idea. Stories precede us and guide us, even to outfox hermetic knowledge, which would often evade the evolutionary principle. In the words of Ian McEwan, through fiction, 'what was once a personal secret is now ours.' [21]. There could be very few people in Australia, for example, who haven't heard stories about travelers dying in the outback when their vehicles break down and their water evaporates. Clearly, humanity has a need for story, as there isn't a culture anywhere in the world that survives without them.

Another distinguishing feature of human brains is that we have very well developed frontal cortexes. These are used to inhibit the storytelling mechanisms in both right and left hemispheres - to choose the stories that we immerse ourselves in [6]. Humans can move beyond the stories that are linked to our physical survival to evolve into deeper thinkers. Storytelling in humans allows for the survival of ideas and ideologies - often those that are metaphysical, abstract and complex. This ability to choose the stories that are relevant to humanity has given us the unique capability of abstraction, imagination and even vision.
Less developed animals have smaller or even non-existent frontal lobes. This means they have considerably less ability to abstract themselves from the narrative of nature, or the simple narratives of reality. The bird referred to earlier, eating seed, doesn't have a choice other than to use their right hemisphere to look out for danger and mates, and use the left to look out for seed. Humans have the ability to put all of those detailed concerns on hold and devote themselves to more abstract activities, for large lengths of time even - perhaps even long enough to read War and Peace [22]. Humans even have the capacity to put aside their hunger in order to pander to abstraction. An animal's sense of ipseity, on the other hand, is constantly channeled towards the most basic needs - there is little capacity for such abstraction.

Storytelling, then, is essential to the way we construct our humanity. It's also vital to our study of the future (as there is no sense of future without a sense of a past - and perhaps this explains our fascination as a species for the study of history). Storytelling is central to humanity because it is through narrative that we learn about ourselves and prepare ourselves for the future in an evolutionary sense. But here's what's interesting: we don't only learn from 'truth' that is verifiable. We learn equally, and potentially even more, from fiction. In words attributed to Ralph Waldo Emerson, 'fiction reveals truth that reality obscures.' The truth that literature provides does not need to prove itself in any empirical way, except in the sense that this truth resonates with the reader's sense of truth. And this, in turn, becomes a point of reference: a story nugget that is stored in the temporal lobes, to emerge as insight and revelation in the context of real life. These nuggets, in turn, become parts of new stories, and together the metanarrative of human culture spins a half-real, half-fictional reality. In the words of David Wilson, the narratives 'that prove most innately satisfying spread and become culture.' When we search only for verifiable 'truth' we miss a historically rich and complete source of data that forms the basis of our humanity [23]. Truth is to be found in empathy, and it is the empathy in storytelling that Benjamin Rahabi is referring to when he states that 'stories have the power to save us.'

\section{References}

1. Le Hunte B (2005) There, Where The Pepper Grows. Fourth State, Sydney, Australia.

2. Burke K (1973) Equipment for Living. University of California Press, Berkeley, USA.

3. Darwin C (1872) The Origin of Species by Means of Natural Selection; Or The Preservation of Favoured Races in the Struggle for Life and The Descent of Man and Selection in Relation to Sex: Modern Library.

4. Spencer H (1874) The Principles of Biology: Appleton.

5. Golembiewski J (2012) Salutogenic design: The neural basis for health promoting environments. World Health Design Scientific Review 5: 62-68.

6. McGilchrist I (2010) Reciprocal organization of the cerebral hemispheres. Dialogues in clinical neuroscience 12: 503-515.

7. McGilchrist I (2011) The Divided Brain. Journal 2011.

8. Le Hunte B (2001) The Seduction of Silence. HarperCollins, Sydney, San Francisco.

9. Burgess N (2002) The hippocampus, space and viewpoints in episodic memory. The Quarterly Journal of Experemental Psychology 55A: 1057-1080.

10. Orwell G (1948) Animal Farm. Penguin Harmondsworth, UK.

11. Baron-Cohen S, Leslie A, Frith U (1985) Does the autistic child have a 'theory of mind'? Cognition 21: 37-46.

12. Brown D (2006) The Da Vinci Code: DC Books. 
Citation: Hunte BL, Golembiewski JA (2014) Stories Have the Power to Save us: A Neurological Framework for the Imperative to Tell Stories.

13. Lucas DW (1968) Poetics. Oxford University Press, Oxford, New York.

14. Kant I (1952) The critique of judgement. Oxford: Clarendon Press.

15. Willett J (1964) Brecht on Theatre. New York: Hill \& Wang.

16. Sass L, Parnas J (2001) Phenomenology of Self-Disturbances in Schizophrenia: Some research findings and directions. Philosophy, Psychiatry, \& Psychology 8: 347-356.

17. Kean C (2009) Silencing the Self: Schizophrenia as a Self-disturbance. Schizophr Bull 35: 1034-1036.

18. Anticevic A, van Snellenberg JX, Cohen RE, Repovs G, Dowd EC, et al. (2012) Amygdala recruitment in schizophrenia in response to aversive emotional material: a meta-analysis of neuroimaging studies. Schizophr Bull 38: 608-621.

19. Chadwick P (1993) The stepladder to the impossible: a first hand phenomenological account of a schizoaffective psychotic crisis. J Ment Health 2: 239-250.
20. Chadwick P (2007) Peer-professional first-person account: Schizophrenia from the inside; phenomenology and the integration of causes and meanings. Schizophr Bull 33: 166.

21. McEwan I (2005) Literature, science and human nature. In: Wilson E, Crews F, Gottschall J, Wilson DS, eds. The literary animal: Evolution and the nature of narrative. Northwestern University Press, Chicago.

22. Tolstoy L (1869 (2006tr)) Война и миръ (War And Peace): Vintage.

23. Wilson E (2005) Forward to the Scientific Side. In: E. Wilson, F. Crews, Gottschall J, Wilson DS, eds. The literary animal: Evolution and the nature of narrative: Northwestern University Press. 